\title{
Sexualidade e identidade no espaço escolar: notas de uma atividade em um curso de educação a distância
}

\section{Sexuality and identity in the school system: notes from an activity in a distance learning course}

\author{
Rosimeri Aquino da Silva ${ }^{1}$ \\ Rosângela Soares ${ }^{1}$
}

\begin{abstract}
RESUMO
$\mathrm{O}$ artigo discute a construção das identidades docentes e discentes no âmbito escolar articulada às questões de gênero e sexualidade. Ele parte da análise de uma experiência de um curso de educação a distância - EaD em que, por meio de uma disciplina específica, buscou-se mapear cenas e ações que foram propostas na escola no sentido de se produzir um debate na área da diversidade. Compreende-se que as identidades constituídas por gêneros, por orientação sexual, por raça/etnia, por classe social, por geração, entre outros marcadores sociais, implicam em diferenças, em distinções vividas por vezes de forma harmônica, e vividas, não raras vezes, de forma conflitiva e/ou violenta. A instabilidade, a incerteza e a transitoriedade atribuídas ao jovem são aspectos que caracterizam também o nosso mundo contemporâneo. Essas novas condições juvenis geram tensões entre os sujeitos envolvidos nas instituições escolares (professoras/es, familiares, e entre as/os próprias/os alunos/as). A análise também permitiu verificar que nas situações de conflitualidade há uma tendência de um culpar o outro revelando: inabilidade dos/ das professoras/es, famílias desestruturadas, alunos/as descomprometidos/ as, entre outros. Argumenta-se que a temática relacionada à diversidade e especificamente à sexualidade e ao gênero compõe fortemente esse cenário de conflitos, apesar das discussões e avanços na compreensão desses temas existentes na sociedade brasileira como um todo.
\end{abstract}

Palavras-chave: sexualidade; gênero; educação; conflitualidades; geração.

DOI: $10.1590 / 0104-4060.36545$

1 Universidade Federal do Rio Grande do Sul. Faculdade de Educação. Porto Alegre, Rio Grande do Sul, Brasil. Av. Paulo Gama, s/n - Prédio 12201. CEP: 90350-070. 


\begin{abstract}
The article discusses the construction of teachers' and students' identities in the school system, articulating it with gender and sexuality issues. It presents an analysis of an experience in a distance education course in which, by means of a specific discipline, it was sought to map scenes and actions that were proposed in the school in order to produce a debate in the area of diversity. Identities consisted of genres, sexual orientation, race/ethnicity, social class, generations, among other social markers, imply differences in living distinctions which are sometimes experienced harmoniously and sometimes in a rather conflicting and/or violent way. The instability, uncertainty and transience attributed to youngsters are also aspects that characterize our contemporary world. These new youth conditions generate tensions between the subjects involved in educational institutions (teachers, families, and among the students themselves). The analysis has also shown that in situations of conflicts there is a tendency to blame each other revealing: the inability of teachers, broken families, uncompromising students, among other factors. It is argued that the themes related to diversity and specifically related to sexuality and gender sharply constitute this scenario of conflicts, despite the discussions and advances in the understanding of these existing topics in the Brazilian society as a whole.
\end{abstract}

Keywords: sexuality; gender; education; conflicts; generations.

Como cenas relacionadas à diversidade no espaço escolar se articulam à construção das identidades contemporâneas? Como é possível problematizar o modo como professores/as olham e narram os modos como seus/suas alunos/ as vivem na escola suas identidades, particularmente em relação à sexualidade? Essas questões estão no centro deste artigo, que discute a construção das identidades no âmbito escolar articulada às questões de gênero e sexualidade. Elas partem de uma experiência de um curso de educação a distância - EaD²

2 A emergência da Educação a distância no campo educacional brasileiro não ocorre sem conflitos. Autores argumentam que essa modalidade de ensino requer respostas prontas, pautadas em uma visão tradicional, impossibilitando um espaço de maior criatividade e reflexividade crítica. (Disponível em: <http://educere.bruc.com.br/CD2011/pdf/5782_3688.pdf>). Além disso, existe a hipótese de que há uma desqualificação do ensino presencial na era da $\mathrm{EaD}$, em que se opta pelo uso generalizado, indiscriminado, barato e banalizado do ensino superior e das especializações lato-sensu. Tratar-se-ia, em última análise, de uma estratégia de mercado neoliberal e de controle dos corpos em meio aberto. (Disponível em: <http://www.revispsi.uerj.br/v9n3/artigos/pdf/v9n3a08.pdf >). O desenvolvimento de novas tecnologias de informação e comunicação foi um fator decisivo para o crescimento, nas últimas décadas, da $\mathrm{EaD}$. Ela também está voltada para a formação de profissionais da educação. Além das implicações que a mesma traz no processo de ensino e de aprendizagem, nos recursos didáticos e na alteração dos espaços e tempos da relação professor e aluno, a EaD emerge 
em que, por meio de uma disciplina específica, buscou-se mapear cenas e ações propostas na escola no sentido de se gerar um debate na área da diversidade. A discussão proposta neste artigo se originou na disciplina nomeada Diversidade de Gênero e de Orientação Sexual: pressupostos, pedagogias e práticas escolares.

$\mathrm{O}$ curso em EaD referido é uma especialização denominada Educação para a Diversidade, iniciado em 2012. Um dos seus objetivos consiste em " [...] contribuir para o enfrentamento de preconceitos e de discriminações de cunho cultural, étnico, de gênero e socioeconômico [...]."33 O curso se insere, portanto, nas discussões da conflitualidade que caracteriza o tratamento escolar das diversas temáticas contemporâneas em um tempo de emergências de múltiplas identidades.

Nesse curso foi ministrada a disciplina III denominada Diversidade de Gênero e de Orientação Sexual: pressupostos, pedagogias e práticas escolares. Como o próprio nome indica, a disciplina se debruça sobre as diversidades de gênero e sexualidade. Para tratar dessas diversidades específicas foram produzidos textos ${ }^{4}$ e vídeos ${ }^{5}$, além de web conferências e aulas presenciais, nas quais se colocaram em pauta discussões que pudessem auxiliar na produção das tarefas exigidas na disciplina: definição e debate de conceitos através da participação em fóruns, produção de textos em atividades presenciais e registro de cenas escolares no Caderno de Registros. Este último é uma atividade do curso que já vinha sendo desenvolvida por outras disciplinas.

Os/as cursistas elaboraram e relataram no Caderno um diagnóstico do ambiente escolar como tarefa específica de outras disciplinas. Com isso, o Ca-

como importante alternativa para a não equidade na oferta de cursos de graduação e pós-graduação, vista a amplitude territorial do país.

3 O Curso de Especialização Educação para a Diversidade é coordenado pela Prof. ${ }^{a}$ Dra. Célia Elizabete Caregnato e tem como público alvo professores/as de escolas públicas. É um curso gratuito, oferecido pelo Programa de Formação Continuada de Professores do MEC. A unidade de ensino mantenedora é da Universidade Federal do Rio Grande do Sul (UFRGS) - Faculdade de Educação/ Secretaria de Educação a Distância (FACED/ SEAD), com apoio da Coordenação de Aperfeiçoamento de Pessoal de Nível Superior/ Universidade Aberta do Brasil (CAPES/ UAB). A carga horária é de 360 horas, o número total de vagas é 400, tendo sido distribuídas 50 vagas nos seguintes polos no estado do Rio Grande do Sul: Agudo, Balneário Pinhal, Cachoeira do Sul, Novo Hamburgo, São Lourenço do Sul, Santo Antônio da Patrulha, Sapiranga e Picada Café. O período de realização é de 26/10/2012 a 18/07/2014. Website: <http://www.ufrgs.br/especializacaodiversidade>.

4 Foram produzidos dois textos específicos para essa disciplina, a saber: A norma é para a gente cumprir ou para a gente transgredir? O complicado equilíbrio das questões de gênero e sexualidade no ambiente escolar e Cenas, intervenção nas cenas e encenação: malabarismos na educação em gênero e sexualidade nas escolas, ambos do professor Fernando Seffner e da professora Rosimeri Aquino da Silva, ministrantes da disciplina em questão.

5 Foi produzido um vídeo de abertura da disciplina III no qual, além dos objetivos da mesma, são discutidos os conceitos e pressupostos que norteiam sua estrutura. 
derno de Registros ganha uma atenção especial por perpassar, de algum modo, a maioria das disciplinas e transversalizar a proposta do Curso. No nosso caso, a atividade proposta para o Caderno de Registros consistiu no pedido para que os/ as cursistas registrassem cenas envolvendo diversidade de gênero e de sexualidade. Para apoiar tal atividade, foi sugerida a leitura de um dos textos produzidos para a disciplina e de alguns filmes e documentários ${ }^{6}$. Ou seja, o pedido era a descrição de cenas escolares que demonstrassem a convivência harmoniosa e/ ou conflituosa no espaço escolar tendo as temáticas da disciplina como foco.

Para a elaboração deste artigo, foram selecionados dois polos de ensino identificados no texto como polos X e Y, a fim de resguardar a identidade e manter o sigilo sobre os registros. A atividade requerida para o Caderno de Registros foi lida, e cenas com alunos/as pertencentes às séries finais do Ensino Fundamental e do Ensino Médio foram selecionadas. Os/as jovens são os/as que mais mobilizam nos/as professores/as as questões relacionadas ao gênero e à sexualidade, algo perceptível nos Cadernos de Registros. Assim, a partir das respostas dos/as professores/as foram selecionados os fragmentos pertinentes para uma reflexão crítica sobre escola e sexualidade, a seguir apresentada.

\section{O que uma atividade em um curso de EaD pode nos dizer sobre identidades e sexualidade juvenil no espaço escolar?}

Teóricos/as do campo cultural têm afirmado que novas paisagens culturais, que se encontram na própria transformação das sociedades modernas do final do século XX, têm desestabilizado as identidades vistas como fixas e imutáveis. No lugar disso, a fragmentação e a contingência das identidades têm abalado certezas de um sujeito único e essencial e seus quadros de referência.

Assim, um desafio se coloca na discussão sobre as identidades: o questionamento do pressuposto humanista de um eu unificado (HALL, 1997; BELSEY, 2002) ou, como aponta Suely Rolnik (1997, p. 19), vivemos em um processo de "constante mestiçagem", fruto da globalização da economia e do avanço tecnológico. Isso significa que o mundo diminuiu de tamanho, ficou menor, como resultado do aumento da velocidade. Os padrões atuais de comunicação tendem

6 Entre os vídeos cito: Minha Vida de João e Era Uma Vez Outra Maria; entre os filmes: Minha vida em cor-de-rosa (Alain Berliner - Bélgica / França / Inglaterra, 1997 - 110min), Acorda, Raimundo... Acorda! (Alfredo Alves - Brasil, 1990, 16min.), XXY (Lucia Puenzo - Argentina, 2007 - 86min.) e As melhores coisas do mundo (Brasil). Inclusive este último foi trabalhado em uma das aulas presenciais. 
a favorecer a transmissão para o mundo de produtos culturais estandardizados. Porém, a globalização traz no seu bojo, ao mesmo tempo, o contato com formas padronizadas de ser e a variedade cultural. Se por um lado há um apagamento das diferenças locais e particulares, por outro alguns fatores relativizam a ideia de uma cultura mundial homogênea e ocidental, como a distribuição irregular da cultura e a própria necessidade da diferença para que a cultura global prospere, no sentido de transformar essa diferença no outro (HALL, 1997).

A linguagem diz respeito às práticas que são indissociáveis do processo de conhecer, ela permite "[...] descrever processos de diferenciação e de hierarquização social e cultural para problematizar as formas pelas quais tais processos produzem (ou participam da produção de) corpos, posições de sujeitos e identidades - como homem e mulher, heterossexual e homossexual [...]" (MEYER, 2012, p. 50). A linguagem, nessa perspectiva, tem uma posição privilegiada na construção e circulação de significados, assumindo uma centralidade para a significação do mundo.

A identidade seria, então, efeito do discurso e não dele precursora ou geradora. A discussão sobre as identidades contemporâneas analisa criticamente a construção da normalização e, com isso, a criação de limites rígidos nos sentimentos, nos desejos e nos atos, estabelecendo, com isso, outros comportamentos e formações sociais como não desejáveis. Tais perspectivas de análise do social permitem afirmar que é por meio de classificações como normal/desviante que se constroem formas rígidas de conhecer, assim como afirmar que o poder se organiza e é distribuído na sociedade. A desnaturalização dos conhecimentos e saberes e seus efeitos sobre indivíduos e grupos têm sido o principal critério para a análise das identidades culturais e sociais, ou seja: de como indivíduos e grupos são produzidos e, ao mesmo tempo, produzem-se no interior da cultura e nas instituições sociais.

Uma reflexão sobre a identidade contemporânea exige questionamentos sobre os significados do ser professor/a, do ser aluno/a, em relação aos quais outras identidades a eles se posicionam sobre quais sistemas simbólicos a representam e como se constituem no espaço escolar. No contexto atual, afirma-se que as identidades, assim como as instituições nas quais tradicionalmente elas se ancoravam, como a família, o trabalho, a igreja, a escola, entre outras, estão em plena crise. A tradição não teria mais o monopólio da autoridade na conduta de comportamentos e consciências (BAUMAN, 2008; HALL, 2005; COSTA, 2004). Contexto este que os/as professores/as apontam igualmente, pois, segundo eles/as, a escola tem dificuldades de ser um espaço de construção identitária no sentido pleno e os/as professores/as não estão obtendo êxito enquanto adultos de referência para as novas gerações (o que seria uma atribuição docente). Essa crise pode ser exemplificada em frases como: 
[...] eles acabam carregando toda essa bagagem, muitos deles têm dificuldades de aprendizagem por terem problemas familiares, como falta de atenção, carinho, alimentação, violência dentro da própria casa, falta de incentivo aos estudos, rejeição da própria família, gravidez na adolescência [...] (Caderno de Registros, polo X)

[...] O professor do curso técnico caminha no corredor da Escola, em frente a uma turma da educação básica, existem meninos e meninas parados todos menores de dezoito anos. O professor pede licença para passar e um aluno grita: "o senhor quer apanhar professor? Vou dar um pau num cara desses qualquer dia". O professor ignora a atitude do aluno por saber que a turma passa por problemas de relacionamento com a direção da escola e com os professores da educação básica, sendo considerada uma turma de alunos com problemas de relacionamento que devem ser tratados [sic] de forma especial, ter um tratamento diferenciado, mas, relata o fato para a diretora da Escola. (Caderno de Registros, polo Y)

$\mathrm{Na}$ avaliação de Juarez Dayrell existe uma nova condição juvenil na atualidade, "[...] um novo jeito de ser jovem [...]" (2007, p. 3), vistas as mutações culturais da atualidade. A instabilidade, a incerteza e a transitoriedade atribuídas ao jovem são aspectos que caracterizam também o nosso mundo contemporâneo. Essas novas condições geram tensões entre os sujeitos envolvidos nessas instituições (professores/as, familiares, e entre os/as próprios/as alunos/ as). Nas situações de conflitualidades há uma tendência de um culpar o outro mostrando: inabilidade dos/as professores/as, famílias desestruturadas, alunos/ as descomprometidos/as etc.

A temática relacionada à diversidade e especificamente à sexualidade $\mathrm{e}$ ao gênero compõe fortemente esse cenário de conflitos, apesar das discussões e avanços na compreensão desses temas existentes na sociedade brasileira como um todo. Além disso, muitas dúvidas e dificuldades ainda persistem no que diz respeito à forma como esta temática deva ser abordada pelos/as professores/ as. Seriam elas questões que importam? Não deveriam ser discutidas apenas no âmbito familiar? Como vinculá-las aos conteúdos escolares tradicionais? Estariam os/as professores/as preparados/as para os debates concernentes ao gênero e à sexualidade?

Talvez uma das dificuldades resida no fato de que a "naturalidade" da sexualidade e do gênero seja algo quase inquestionável. Ambos são ainda considerados, inclusive no âmbito escolar, atributos dados, essenciais a uma suposta natureza humana. Assim, é interessante questionar: que concepções de 
gênero e sexualidade se tornaram naturalizadas? E ainda, o que implica essa naturalização? Que discriminações e exclusões tais concepções constroem? De que maneira constituímos a sexualidade como fator central da nossa existência? Essa construção é igual para homens e mulheres?

Sem desconsiderar as dificuldades apontadas por professores/as, pode-se observar nas cenas transcritas que a juventude é colocada como problema, a/o jovem é, ao mesmo tempo, uma ameaça para si e para o grupo que o cerca. A visão do adulto em relação ao que vem da juventude representa situações de risco, e a sexualidade é um dos pontos centrais desse risco: gravidez precoce, doenças sexualmente transmissíveis, entre outras, reforçam a ideia de que o que vem desse grupo deve ser olhado com desconfiança e receio (SOARES, 2000; GIROUX, 1996). O que permanece é a ideia de controle da sexualidade, pois as/os jovens são consideradas/os, ao mesmo tempo, indivíduos com o desejo sexual em evidência e imaturos. Tal posição tem efeitos muitas vezes traduzidos numa desesperança e em um pânico com as novas gerações e a educação escolar.

Ser jovem é também uma posição desejada e admirada. Na juventude são depositadas perspectivas futuras de realizações pessoais, de descobertas, de experimentações e de definições, sejam elas profissionais ou mesmo sexuais. À juventude estão associadas potencialidades. Há desafios e dilemas que lhes são comuns, seja no domínio do lazer, do consumo, da participação social ou da sexualidade. Em se tratando de cultura juvenil, a sexualidade ganha especial relevo na medida em que sexualidade e identidade juvenil preservam uma estreita conexão.

Ao argumentar esse compartilhamento não está sendo sugerida uma homogeneidade nas formas de viver a juventude. Ao contrário, concebe-se a cultura juvenil como uma construção cultural relativa no tempo e no espaço. Há distintas maneiras de ser jovem na intensa heterogeneidade que se observa no plano econômico, social e cultural. O argumento é que pertencer a uma determinada geração remete ao momento histórico em que se está vivendo. No campo da sexualidade significa afirmar que determinado período histórico tem sua particular configuração, significados e conflitos. São experiências distintas em cada geração. Além disso, cabe ainda apontar que a juventude, embora representada como inovadora, relacionada ao presente, transformadora e transgressora, parece estar muitas vezes clandestina nessa representação. As experiências sociais dos/as jovens e as maneiras como elas são expressas resultam muitas vezes em intervenções que têm um caráter de controle e contenção.

A complexidade na relação entre a escola e o meio social, as incongruências entre o tempo social da escola e as expectativas diferenciadas das populações escolares indicam uma espécie de fosso instransponível entre adultos e jovens, 
entre culturas juvenis e a cultura dos adultos, entre as preocupações de jovens e as preocupações dos mais velhos (BAUMAN, 2011; DAYRELL, 2007).

A este quadro das instituições, tido como em crise, soma-se a visibilidade de novos grupos sociais que questionam as identidades hegemônicas, a saber, identidades brancas, masculinas e heterossexuais. São grupos sociais formados por identidades subalternas, historicamente marginalizadas que vêm a exigir direitos, quebrar normas e contestar verdades historicamente construídas e até então consideradas eternas.

A escola é um espaço onde é possível observar a emergência de conflitos em torno da visibilidade desses novos grupos sociais que buscam afirmar suas formas de vida até então subjugadas. A reação a esses grupos e suas pautas e assuntos polêmicos se dão de forma muitas vezes conflitiva e até violenta. Seus comportamentos tidos como estranhos e/ou impuros parecem não só rondar o território escolar, mas também compô-lo, o que exacerba as disputas entre grupos. Tais disputas não são apenas opiniões distintas sobre um tema, elas são lutas em torno do poder de ditar as normas do gênero e da sexualidade. Algumas situações descritas por professores/as no Caderno de Registros ilustram essas lutas:

[...] havia uma menina do $8^{\circ}$ ano que estava namorando outra menina. Esta situação causou tanto incômodo nos docentes, que relatavam não entender aquela menina, tão bonita e de família, [que] estava cometendo um erro deste. Os professores ficavam fazendo comentários pejorativos quando a namorada ia buscar a aluna na saída da escola. Em outra situação a escola fez um passeio aberto à comunidade escolar, mas a menina foi advertida pela orientadora da escola que não poderia levar a namorada. (Caderno de Registros, polo X).

No ano passado tive uma aluna na $8^{\mathrm{a}}$ série que era jogadora de futebol, usava roupas esportivas da moda de jogador de futebol. Esta menina estava na biblioteca quando a professora bibliotecária a chamou: "Tu o menino..." Ela na mesma hora respondeu: "Eu sou menina, meu nome é..." Esta aluna constantemente tinha que afirmar no espaço escolar a sua identidade feminina que na ideia dos professores estava dissociada da prática de futebol por mulheres. (Caderno de Registros, polo X).

Em uma turma de Ensino Fundamental, no turno da manhã, há uma menina que, há uns dois anos atrás, seu estilo era "normal". Em 2012 ela mudou radicalmente seu estilo de se vestir, começou a vestir-se de 
preto, cabelos pintados de preto, acessórios e maquilagem escura. Em uma manhã dessas ela perguntou a seu professor de matemática se a secretária da escola era bissexual, que se fosse ela tinha interesse nela, pois já havia tido uma experiência com uma outra menina e tinha gostado. (Caderno de Registros, polo Y).

Ser mediador de um conflito como, por exemplo, de um aluno que aos 13 anos se identifica muito mais com traços femininos do que masculinos é um grande desafio em nosso cotidiano. (Caderno de Registros, polo X).

O crescimento da visibilidade das diferentes orientações sexuais e das diferentes posições de gênero traz consequências na vida de todos, desestabiliza as instituições que tradicionalmente ajudaram a definir a regra e a norma moral. Isso ajuda a explicar a diversidade de marcas de gênero, independentemente dos sexos biológicos, encontrados entre os/as alunos/as e entre os/as professores/as hoje em dia. Alguns dos exemplos trazidos ilustram o abalo que algumas instituições sofrem quando confrontadas naquilo que tradicionalmente ajudaram a definir como normas morais de comportamento, baseadas na heteronormatividade. $\mathrm{O}$ imperativo heterossexual, nas palavras de Judith Butler, “[...] possibilita certas identificações sexuadas e impede ou nega outras identificações" (BUTLER, 2001, p. 155).

A escola pode ser um exemplo da reiteração da norma heterossexual, pois ela norteia seus currículos e práticas a partir de um padrão único, que nega outras sexualidades ou tenta "corrigi-las" (LOURO, 2000; 2002). As escolas produzem significados a respeito de sexualidade tida como normal, assim como produzem exclusões. Esses significados engendrados em relações de poder normatizam e ajudam a subjetivar os sujeitos que delas participam: seus/suas professores/ as, equipe técnica e administrativa, alunos/as. As escolas, assim como outras instituições sociais, colocam de forma dicotômica e classificatória o que é certo e errado, que comportamentos são aceitáveis ou não. Elas estão, portanto, implicadas na produção dos sujeitos que delas fazem parte. Através de suas normas, do uso do tempo, do espaço, das suas rotinas, a escola sempre esteve envolvida no processo de construção de identidades sociais. As diferenças como gênero e sexualidade são ativamente produzidas na escola. Ela produz e recria significados, assim o repertório cultural de alunos/as e professores/as adquire na dinâmica escolar novos significados.

A escola, que é um lugar de conhecimento, muitas vezes produz o "ocultamento" em relação à sexualidade. Nas situações em que as questões relacionadas 
à sexualidade se evidenciam, alguns indivíduos são utilizados como "indivíduos míticos", como depositários da sexualidade. Tal com Debbie Epstein e Richard Johnson (2009) observaram, tais indivíduos fazem parte da produção de dessexualização da escola na medida em que eles são considerados os "outros", e oscilam entre o lugar de vítima e culpado pela situação.

As cenas escolhidas e descritas no Caderno de Registros de professores/ as são exemplos de como cada instituição ou atividade social gera seu próprio universo de significados e práticas e trabalha com ele. Essas práticas educativas são reconhecidas como fundamentalmente políticas, pois as escolas e suas formas específicas de pedagogia são locais de produção de significados, forjados em relações de poder. O processo de escolarização se constitui de práticas sociais, ao mesmo tempo em que produz, organiza e regula ideias e concepções sobre que ações são possíveis e legítimas. As identidades são reconhecidas como instáveis, incompletas e em processo. Isso não significa a perda de seu aspecto político; ao contrário, pode apontar para novas formas de luta. São nas próprias práticas cotidianas que se constroem formas de viver a sexualidade e o gênero e são também nessas práticas que se geram possibilidades criativas e inovadoras. Não é um produto acabado, é um processo que está sempre sendo refeito.

Já é possível perceber em algumas escolas ações que apontam direções mais democráticas, ou, o que também é muito importante, o reconhecimento de que necessitam discutir e pensar em formas de trabalho que incorporem a todos/as.

Nós professores também contribuímos e muito para que haja esta discriminação quando percebemos que um aluno apresenta características diferentes dos demais daquele grupo insistindo e mantendo as mesmas regras para todos, não respeitando as individualidades, as opções e as preferências de cada um. (Caderno de Registros, polo X).

Para que possamos trabalhar adequadamente sobre as questões que envolvam as diferenças entre gênero e sexualidade precisamos nos adaptar e nos adequar a esta realidade, precisamos entender e até mesmo nos adaptarmos com esta nova visão de gênero e sexualidade. (Caderno de Registros, polo X).

A formação identitária (ser aluno/a, ser professor/a) nos espaços da escola da atualidade implica em processos subjetivos, em representações e em senti- 
dos múltiplos aprendidos muitas vezes em situações denominadas por alguns profissionais de "front" de batalhas. No que tange ao docente, configuram-se, na contemporaneidade, algumas conflitualidades nesta experiência e neste ofício. A eles/elas, professores/as, no exercício de suas funções, são postas em circulação um conjunto de representações relativas "[...] aos modos de ser e agir dos professores" (GARCIA; HYPOLITO, 2005, p. 48). Professores/as são cotidianamente interpelados por uma variedade de discursos que disputam a verdade sobre suas ações e seus ofícios frente às mais diversas situações que ocorrem na escola (GARCIA; HYPOLITO, 2005). Apesar das/os professores/as ocuparem uma posição considerada estratégica e fundamental para a formação das novas gerações, também circulam socialmente falas acerca da desvalorização desta profissão quando comparadas a outras. (TARDIF, 2002).

De acordo com a avaliação de alguns/algumas professores/as, como se não bastassem as problemáticas típicas que têm acompanhado a trajetória do ser professor/a (más condições de trabalho, salários indignos, desrespeito e excesso de carga horária), a eles/elas também são colocadas questões contemporâneas complexas, tais como as relacionadas ao gênero e à sexualidade. Elas não são questões novas e estão longe de serem simples, são questões que se complexificam cada vez mais na cultura atual. Professores/as parecem perplexos frente às exigências colocadas para elas/es no cotidiano de trabalho, o que se exemplifica por meio de vários questionamentos trazidos:

Sei que não consegui mudar sua opinião [refere-se ao aluno que fez comentários negativos] sobre o assunto. A discussão não serviu em nada para que houvesse mudanças em seus valores, tanto é que na outra semana ele trocou de turno alegando necessidade de trabalhar no turno contrário. Estas situações acabam nos frustrando como educadores. (Caderno de Registros, polo Y).

A maioria desiste do magistério. Você vai desanimando quando percebe que todos parecem descomprometidos. Tem dias que a vontade é desistir de tudo e falar como muitos: estou abandonando o magistério. (Caderno de Registros, polo Y).

O que fazer com alunos que mudam seu nome de batismo? Com meninas com tanta iniciativa sexual? (Caderno de Registros, polo Y). 
Os diversos posicionamentos e atuações dos/as professores/as em torno dos debates concernentes a gênero e sexualidade também são ilustrativos das diferenças de posicionamento que existem entre eles/as em torno dessas temáticas. Alguns/algumas professores/as aderem às discussões, buscando aprofundar conhecimentos e desenvolvendo atividades. Outros/as procuram eximir-se. E, ao assumirem essa postura, afirmam desconhecer formas de lidar com essa questão, pois não conhecem nada a respeito sobre outras formas de sexualidade além da norma.

Há casos em que a formação de casais homossexuais assusta a nós professores por não sabermos como lidar com essas manifestações. Para alguns colegas nada mais é do que uma forma de contestar o mundo no qual eles estão vivendo. Assim, muitos de nós professores fazemos de conta que estes assuntos não são pertinentes, e estes personagens ficam invisíveis. Passamos pelos corredores e não enxergamos tais fatos, pois estas manifestações não nos interessam ou nos assustam, tanto que preferimos fingir que não vemos.

É preciso pensar na construção de metodologias para levarmos o tema sexualidade e gênero para dentro da escola de maneira que possamos esclarecer nossos alunos e auxiliá-los para uma vida plena e mais feliz independentemente de suas escolhas. (Caderno de Registros, polo X).

As famílias foram na escola dizer que estavam muito preocupadas com os jeitos deles se comportarem. A escola disse que não via problema nenhum neles, que eram excelentes estudantes e que ali naquela instituição as pessoas precisavam se sentir bem e serem respeitadas pela sua maneira de ser e de agir, independentemente de qualquer coisa. Além disso, após uma fala das famílias insinuando a preferência sexual dos meninos, a escola colocou que o importante eram eles serem felizes, que isso não era defeito algum. (Caderno de Registros, polo $\mathrm{X}$ ).

Preconceito não está com nada. Deixa "o cara" ser feliz. (Caderno de Registros, polo X).

Deborah Britzman $(1996 ; 1999)$ é uma das autoras que reflete sobre o mito da ignorância. Ela argumenta que posturas como essa carregam junto um gosto pelo não conhecimento, ilustradas em frases como: "não sei nada sobre gays"; 
"isto não faz parte do meu círculo"; "não sei como trabalhar esses assuntos". Junto com isso, ela afirma que o desconhecimento da homossexualidade é também o desconhecimento da heterossexualidade, pois ambas são resultantes de um processo de negociações complexas que se dão ao longo da vida. A forma como a sexualidade é tratada na escola apoia-se em mitos baseados na heteronormatividade. A esses mitos associa-se a ignorância como uma forma de proteção. A ideia é que quanto menos os jovens souberem sobre o "homossexualismo" (uma expressão patologizante e bastante usual), tanto mais estarão protegidos em relação a ele. O que perpassa esse mito é o fato de que as pessoas e as informações simpáticas poderiam estar cooptando os jovens. Ainda de acordo com a autora, em certa medida, o mito está correto, pois exemplos de comunidades gays podem ser interessantes no sentido de relativizar o privilégio da heterossexualidade. Porém, o pressuposto é que o conhecimento e as pessoas são nocivos. Um exemplo local acerca desse mito foi o embate que se deu entre setores políticos/religiosos e o Ministério da Educação referente à produção de materiais educativos que abordavam temas relativos às políticas afirmativas e à diversidade sexual. $\mathrm{O}$ argumento de opositores contra a divulgação desses materiais se fundamentou na ideia de que a escola incentivaria práticas e comportamentos sexuais contrários às leis naturais.

Dessa forma, o argumento de que os estudantes são muito jovens para se definirem sexualmente está relacionado à ideia de que eles são imaturos para lidarem com essas questões. Ele também não é incomum para aqueles que julgam inadequado trabalhar as temáticas de gênero e de sexualidade na escola. E, por fim, os mitos associam-se à sexualidade como unicamente de caráter íntimo e privado, não tendo nada a ver com a esfera social. As representações da sexualidade na juventude e os mitos que perpetuam determinados padrões sexuais resultam na impossibilidade de a escola conviver com diferentes contextos culturais.

Porém, parece haver outro componente interessante nessa discussão contemporânea: o apelo à questão da felicidade. É possível questionar se ser feliz está se convertendo em uma nova e outra verdade. Pascal Bruckner (2002) é um dos autores que tem se debruçado sobre o imperativo da felicidade. Ele afirma que essa é uma ordem que carrega um dilema, pois com isso perdemos de não vivermos (sempre) satisfeitos e felizes. A ideia de sofrimento está fora de cogitação e, ao contrário disso, há sempre uma busca incessante de prazer, euforia e movimento, denominada por Jurandir Costa (1998) como a era da "cultura das sensações".

Assim como a sexualidade tem especificidades se relacionada à juventude, "a nova ordem moral" de felicidade, quando relativa à juventude, também ganha contornos mais nítidos. Como já referido, ser jovem dá prestígio. Em 
nosso tempo, juventude está ligada a corpo e imagem e, como um produto a ser consumido, produz e comercializa mercadorias que prometem o prolongamento do tempo articulado a uma imagem juvenil (SANT'ANNA, 2002).

Argumentos do campo sociológico demonstraram (SILVA, 2010) que a relação da escola com as particularidades culturais dos grupos que compõem o espaço social é marcada por uma violência simbólica do saber escolar, exercida por hábitos sociais, pelos/as professores/as e funcionárias/os da instituição: uma relação de poder que impõe um conjunto de valores ao conjunto da população envolvida. Há uma frequente disposição para falar da origem social, da condição étnico-racial ou das famílias, que muitas vezes são consideradas como desestruturadas.

A Antropologia, assim como estudiosos/as do campo cultural da atualidade, tem ensinado acerca do etnocentrismo entre as culturas, como também tem trazido diversas contribuições para o entendimento das relações entre as diferenças culturais. O novo, o diferente pode nos afetar de diferentes formas, sendo que podemos lidar com ele de forma civilizada, cordial, mas também podemos estranhá-lo, pois o diferente, em última análise, coloca em xeque nossas certezas.

No que diz respeito aos marcadores identitários de gênero e sexualidade, sabe-se que a história, a cultura, assim como processos subjetivos ocorridos no seio das instituições, sejam elas instituições de segurança, sejam da saúde, ou da educação, fixam lugares, naturalizam discriminações e permitem a formação de contextos nos quais os insultos direcionados aos grupos sociais tidos como menos importantes se tornam banalizados. A discriminação, velada ou não, encontra ressonância no ambiente escolar, nas relações societárias, nos currículos, na naturalidade e na banalização de preconceitos.

Ao trabalhar o marcador identitário relativo às relações de sexualidade e também de gênero, nos deparamos com a constatação de que as relações tradicionalmente hierarquizadas entre homens e mulheres, heterossexuais e comunidade LGBT (Lésbicas, Gays, Bissexuais, Travestis, Transexuais e Transgêneros) encontram reforço no campo escolar.

Este é um tempo de profundas mudanças sociais, culturais, estéticas, assim como de mudanças na própria forma de controle e de dominação social. Essas mutações teriam influenciado, inclusive, a forma de perceber as inúmeras distinções identitárias que conformam o solo educacional. As identidades de docentes e discentes, assim como as de outros atores sociais da educação seriam percebidas como diversas, como múltiplas. Se existe a hipótese de que a multiplicidade, a diferença e as heterogeneidades culturais compõem as identidades no contemporâneo, cabe o questionamento: como se dá a percepção cotidiana das diferenças e diversidades culturais e sociais? É possível lidar de 
forma consensual, harmônica e tolerante com as denominadas diferenças que hoje povoam o cenário escolar ou lidamos de forma conflitiva, reforçando preconceitos e estereótipos? Talvez seja possível afirmar que ambas as respostas estão corretas, pois ambas são encontradas em diversos contextos escolares.

Há identidades constituídas por gêneros, por orientação sexual, por raça/ etnia, por classe social, por geração, entre outros marcadores sociais, implicando em diferenças, em distinções vividas por vezes de forma harmônica e consensual. E vividas, não raras vezes, de forma conflitiva e/ou violenta. O campo educacional é um lugar de fundamental importância para a constituição de representações, sejam aquelas que buscam sedimentar preconceitos, sejam aquelas que buscam construir espaços de mudança e resistência.

No Caderno de Registros é possível identificar um emaranhado de discussões e disputas. É perceptível que as instituições e, nesse caso, a escola, estão cada vez mais limitadas para apresentar soluções para esses problemas. Com a reflexão crítica neste texto, buscam-se situar tais disputas em um cenário mais amplo. Há algumas pistas, mas o cenário ainda não é totalmente conhecido (isto é possível?). Ainda é difícil abordar com a devida clareza o impacto na trajetória escolar desses novos contextos.

Crise também significa transição, um mundo que não é mais, mas que também ainda não é; ele está por vir. A referência aqui é uma descrição do que ainda acontece, e também de outro movimento que inventa, e em alguma medida cria novas possibilidades. Este texto é entendido como uma forma de examinar de que modo a sexualidade serve para diferenciar e posicionar determinados/as alunos/as como alvo de controles mais sistemáticos por entendermos ser essa uma colaboração com os grandes desafios dos tempos atuais da nossa sociedade e da escola em particular: a coexistência da diversidade.

\section{REFERÊNCIAS}

BAUMAN, Zygmunt. Vida para o consumo. Rio de Janeiro: Jorge Zahar Editor, 2008. BAUMAN, Zygmunt. 4 cartas do mundo líquido moderno. Rio de Janeiro: Jorge Zahar Editor, 2011.

BELSEY, Catherine. Poststructuralism: a very short introduction. New York: Oxford, 2002.

BRITZMAN, Deborah. O que é esta coisa chamada amor: identidade homossexual, educação e currículo. Educação e Realidade, Porto Alegre, v. 21, n. 1, p. 71-96, jan.jun. 1996. 
BRITZMAN, Deborah. Curiosidade, sexualidade e currículo. In: LOURO, Guacira (Org.). O corpo educado: pedagogias da sexualidade. Belo Horizonte: Autêntica, 1999. p. 83-112.

BRUCKNER, Pascal. A euforia perpétua: ensaio sobre o dever de felicidade. 2. ed. Rio de Janeiro: Difel, 2002.

BUTLER, Judith. Corpos que pesam: sobre os limites discursivos do sexo. In: LOURO, Guacira Lopes (Org.). O corpo educado: pedagogias da sexualidade. 2. ed. Belo Horizonte: Autêntica, 2001. p. 151-172.

COSTA, Jurandir Freire. Sem fraude nem favor: estudos sobre o amor romântico. Rio de Janeiro: Rocco, 1998.

COSTA, Jurandir Freire. O vestígio e a aura: corpo e consumismo na moral do espetáculo. Rio de Janeiro: Garamond, 2004.

DAYRELL, Juarez T. A Escola "faz" as juventudes? Reflexões em torno da socialização juvenil. Educação e Sociedade, Campinas, v. 28, n. 100- Especial, p. 1105-1128, out. 2007.

EPSTEIN, Debbie; JOHNSON, Richard. Jovens produzindo identidades sexuais. Revista Brasileira de Educação, Rio de Janeiro, v. 14 n. 40, p. 83-92, jan./abr. 2009.

GARCIA, Maria Manuela Alves; HYPOLITO, Alvaro Moreira; VIEIRA, Jarbas Santos. As identidades docentes como fabricação da docência. Educação e Pesquisa, São Paulo, v. 31, n. 1, p. 45-56, jan./abr. 2005.

GIROUX, Henry. O filme Kids e a política de demonização da juventude. Educação e Realidade, Porto Alegre, v. 21, n. 1, p. 123-136, jan./jun. 1996.

HALL, Stuart. A centralidade da cultura: notas sobre as revoluções de nosso tempo. Educação e Realidade, Porto Alegre, v. 22, n. 2, p. 15-46, jul./dez. 1997.

HALL, Stuart. A identidade cultural na pós-modernidade. 10. ed. Rio de Janeiro: DP\&A, 2005.

LOURO, Guacira. Corpo, escola e identidade. Educação e Realidade, Porto Alegre, v. 25, n. 2, p. 59-75, jul./dez. 2000.

LOURO, Guacira. Currículo, gênero e sexualidade: refletindo sobre o "normal", o "diferente" e o "excêntrico". Labrys: estudos feministas. Brasília, v. 1, n. 1/2, jul./dez. 2002. Disponível em: <http://www.unb.br/ih/his/gefem/>. Acesso em: 27/12/ 2013.

MEYER, Dagmar Estermann. Abordagens pós-estruturalistas de pesquisa na interface educação, saúde e gênero: perspectiva metodológica. In: MEYER, Dagmar; PARAÍSO, Marlucy (Orgs.). Metodologias de Pesquisas Pós-Críticas em Educação. Belo Horizonte: Mazza Editores, 2012, p. 47-61.

ROLNIK, Suely. Toxicômanos de identidade. Subjetividade em tempo de globalização. In: LINS, Daniel (Org.). Cultura e subjetividade: saberes nômades. Campinas: Papirus, 1997. 
SANT'ANNA, Denise B. de. Transformações do corpo: controle de si e uso dos prazeres. In: RAGO, M.; ORLANDI, L. B. L,; VEIGA-NETO, A. (Org). Imagens de Foucault e Deleuze: ressonâncias nietzschianas. Rio de Janeiro: DP\&A, 2002, p. 99-110.

SILVA, Rosimeri Aquino da. Resenha: Violências e conflitualidades. Revista Sociedade e Estado, Brasília, v. 25, n. 2. maio/ago., 2010.

SOARES, Rosângela. Adolescência: monstruosidade cultural? Educação e Realidade. Porto Alegre, v. 25, n. 2, p. 151-162, jul./dez. 2000.

TARDIF, Maurice. Saberes docentes e formação profissional. Petrópolis, RJ: Vozes, 2002.

Texto recebido em 19 de maio de 2014. Texto aprovado em 20 de maio de 2014. 